\title{
Mysteries about drug metabolism in the obese weigh on doctors
}

The surgery was a success, but a question loomed after the procedure: given that the patient was obese, what was the right antibiotic dose? "The thought was, well, she's twice as big as a normal person, so we'll give her twice the dose," says Aaron Cook, a clinical pharmacy specialist at the University of Kentucky in Lexington. "For that drug, levofloxacin, there's just no information to go on, no dosage recommendation for obese patients."

The patient fared well, but such conundrums are becoming increasingly common as obesity rates rise around the globe. Just a month ago, researchers released new figures estimating that the US will see an additional 65 million obese individuals by 2030 (Lancet 378, 815-825, 2011). Already in the country approximately one in three adults and one in six children are obese-a condition that can precipitate heart disease, diabetes, respiratory failure and other illnesses that often require medication. But experts say that merely doubling the dose isn't the solution because the physiological changes that accompany obesity, such as increases in the volume of blood pumped by the heart and fat mass, can in turn lead to changes drug absorption and metabolism.

Chandrahas Sahajwalla, who conducts pharmacological research at a US Food and Drug Administration (FDA) office in Silver Spring, Maryland, has tried calling attention to the paucity of information in this area. A comprehensive review by Sahajwalla and his colleagues published in July found that, to date, only a handful of approved drugs carry meaningful label information regarding obesity, such as specific dose adjustment (Clin. Pharmacol. Ther. 90, 77-89, 2011).

"Unless a specific drug is studied in obese patients during drug development, it's very difficult to extrapolate not only pharmacokinetics but also efficacy and safety information from normal-weight individuals to obese patients," Sahajwalla says. "The main hurdle is lack of sufficient number of patients with varying degree of obesity in clinical trials."

It's not that they're excluded. The FDA, for instance, encourages pharmaceutical companies to enroll obese subjects to collect data for dosing recommendations, says Sahajwalla. He's hopeful that as the scientific community continues to shed light on the need for actively including this population in trials, drugmakers will respond.

There are various efforts already underway to learn more. Earlier this year, for instance, Italian scientists proposed a systematic approach to dosing recommendations for anesthesia medications (Best Pract. Res. Clin. Anaesthesiol. 25, 27-36, 2011). And another group of Italian clinicians is currently conducting a three-year study looking at the changes in drug metabolism and pharmacokinetics in patients with morbid obesity after bariatric surgery.

In Cook's case, the lack of information prompted him and his colleagues to conduct their own study. They administered a single 750-milligram intravenous dose of levofloxacin to obese individuals who were hospitalized as well as those who were otherwise healthy. Their findings, published this summer, revealed that although peak concentrations of the antibiotic in both groups were comparable to that in normal-weight individuals, the elimination of the drug from the body was accelerated in the nonhospitalized obese arm (Antimicrob. Agents Chemother. 55, 3240-3243, 2011). The findings are medically relevant, Cook notes, because faster clearance of the antibiotic might make those patients more vulnerable to infection. "It's concerning," he says, "because our data suggested that drug exposure would be almost half what it would be in a normal-weight individual, which might lead to more failures in obese patients."

The study may have answered Cook's original question, but it also highlights how much remains unknown: "The more that we learn about how drugs behave in obese individuals," he says, "the more we find that one size doesn't necessarily fit all."

Alisa Opar

\section{Ten years on from anthrax scare, analysis lags behind sequencing}

A decade ago this month, a microbiologist at Northern Arizona

University, in Flagstaff, took a special delivery from the US government. Federal investigators wanted the scientist, Paul Keim, to identify the anthrax that appeared in letters mailed to news organizations and US lawmakers. Overnight, he used PCR to determine that the anthrax sent was the Ames strain, commonly used in research - but that was just the beginning of a scientific investigation that would catapult the still wet-behind-the-ears science of microbial forensics to the forefront of the criminal inquiry.

Ten years on, Keim's PCR-based technique seems downright quaint in comparison with modern, speedy DNA sequencing. "In a lot of ways we've matured," says Bruce Budowle of the University of North Texas Health Science Center in Fort Worth. But there are challenges ahead, adds Budowle, who retired in 2009 from the US Federal Bureau of Investigation (FBI), where he was involved in the anthrax studies as a senior scientist in the laboratory division: "In a lot of ways, we've got a long way to go... We haven't grown in the interpretation of the results and what they might mean."

Overall, the country has improved in many aspects of preparedness. The US government spent $\$ 60$ billion on biodefense over the last decade, including the 2004 founding of Project BioShield. The $\$ 5.6$ billion initiative, managed by the government's Biomedical Advanced Research and Development Authority (BARDA) since 2006, is charged with stockpiling medicines and funding research on new therapies that could be used in instances of bioterrorism. And the spending continues: last month, BARDA awarded a five-year $\$ 68$ million contract to the New Jersey company Elusys Therapeutics to develop a prophylactic treatment against anthrax.

At the same time, investments continue in the area of microbial forensics, which encompasses chemical analysis, carbon dating and microscopy in addition to DNA sequencing. Shortly after the 2001 anthrax scare, the FBI and Department of Homeland Security created the National Bioforensic Analysis Center, housed at the US Army Medical Research Institute for Infectious Diseases (USAMRIID) in Fort Detrick, Maryland. (Ironically, USAMRIID employed Bruce Ivins, who committed suicide in 2008 around the time he was fingered by the $\mathrm{FBI}$ as the culprit behind the anthrax letters.) Researchers there have converted medical tests-intended to identify pathogens in blood samples-to work for other kinds of evidence such as soil samples, carpet fibers and clothing.

Although next-generation DNA sequencing has radically accelerated the decoding of pathogen genomes since 2001, analysis techniques have not kept pace. "The biggest challenge 